\title{
MUTAÇÕES NA PRÁTICA CRÍTICA
}

\author{
Fabio Akcelrud Durão \\ Universidade Federal do Rio de Janeiro \\ fad2@duke.edu
}

\begin{abstract}
Resumo: $O$ presente texto investiga recentes modificações na prática da crítica filosófica. Em sua parte inicial, delineia rapidamente as principais determinações do conceito de crítica, bem como estabelece a ligação entre crítica e crise. Isto é seguido por uma descrição da prática crítica de T.W. Adorno, na qual são apontadas: a) a valorização da leitura micrológica em um contexto de precarização do conceito de totalidade; b) a problematização de uma linearidade temporal por meio da imbricação entre história e natureza; c) a crescente opacidade da linguagem filosófica diante da proximidade de seu objeto. A última parte do texto volta-se para desenvolvimentos recentes da critica que acentuam as transformações introduzidas por Adorno. Em Derrida, há autonomização do detalhe; em Slavoj Žižek perde-se a diferenciação entre objeto e instrumento de análise; em Deleuze e Guattari, ocorre a dissipação da distância hermenêutica.
\end{abstract}

Palavras-chave: Crítica, T.W. Adorno, teoria.

Muitas vezes algo só dá a ver seus contornos quando se esvai a força que possuía aparecendo apenas na fraqueza que se segue ao seu esvanecer (e que em alemão tem uma fórmula justa: Wesen ist, was gewesen ist, ser ou essência é aquilo que foi). Isso é o que aconteceu com o conceito de crítica. Que ele seja um fruto do movimento mais amplo da Aufklärung, do Iluminismo ou Esclarecimento, é sabido; pois a prática crítica põe em cena vários fatores ${ }^{1}$ - não tanto como pressupostos lógicos, mas antes como verdadeiras conquistas históricas. O primeiro desses fatores é a liberdade para se inquirir sobre qualquer coisa, colocar o que quer que seja diante dos olhos. Isto pressupõe que nada é intocável e que nada deve ter sua existência justificada como simplesmente dada. Ao invés de pertencer a um 
estado fixo de coisas, a uma ordem imutável, o mundo apresentase, sob a égide da crítica, como algo temporalizado: os costumes e hábitos, as crenças, as práticas coletivas, as formas de governo, as religiões, as opiniões - todas podem tornar-se objeto de interrogação. Sem dúvida, a crítica existe apenas como tal quando se debruça sobre algo de humano e, conseqüentemente, passível de mudança (fazer uma crítica da lei da gravidade não faz sentido); no entanto, dentro dos limites daquilo que é feito pelo homem, limites em contínua e estonteante expansão, a crítica, em seu desenvolvimento histórico, exibe a pretensão de total liberdade. Além disso, é importante observar que a crítica está estreitamente relacionada com a prática, pois ao ter um ser-outro como seu horizonte, como um pressuposto para que possa ser enunciada, ela implica mudança e transformação, por mais distante ou improvável que possam parecer.

Tal ser-outro, no entanto, apresenta-se de formas distintas de acordo com a modalidade de crítica em questão. Se ela toma como apoio uma discrepância entre o objeto e o que ela designa como a realidade, então a crítica será empírica; caso identifique um desacordo no seu próprio objeto, por assim dizer, entre o que proclama ser e o que de fato é, será imanente; se guiada por critérios pertencentes ao próprio crítico receberá o nome de transcendente; se tiver como base as precondições do próprio ato crítico será transcendental; por fim, uma vez que compare seu objeto com aquilo que deveria ou poderia ser (o sollen do alemão ou o ought to do inglês) será normativa. É claro que essas distinções têm algo de artificial, não podendo ser concebidas como absolutas, já que podem ser combinadas de diversas maneiras em estruturas argumentativas concretas; comum a todas elas, todavia, é sua aspiração ao rigor, tanto em relação à análise de seu objeto, quanto à forma de exposição. A crítica investiga aquilo que coloca à sua frente (objeto: ob-jacere), averiguando sua coerência interna, a organização de seus diversos componentes, as relações que entretêm com outros itens da experiência ou do mundo; por outro lado, deve apresentar seu discurso de forma clara e de maneira 
tão simples quanto possível. Fica, assim, manisfesta a estreita relação entre crítica e razão, uma vez que é esta que atuará ao mesmo tempo como instrumento e objetivo da investigação: "instrumento", como ferramenta da cognição, da análise, e "objetivo”, como alvo do processo de esclarecimento do mundo, de transformação do universo humano em um todo racional, visando à harmonia entre os indivíduos e em sua relação com a natureza. Isso implica, ainda, que a razão passa também a determinar um sujeito que a possui e que a exerce, o ser humano, racional por definição.

Eis um circuito que, por conter a ratio em todas suas partes, parece apaziguador. No entanto, basta uma simples observação etmológica para que todo um novo panorama surja diante de nossos olhos: "crítica” e "crise" têm a mesma raiz grega, - ñuíù. É impossivel ignorar que, de uma forma ou de outra, crítica e crise sempre andaram de mãos dadas, pois nem mesmo na época mais heróica da prática crítica, na luta da burguesia emergente contra o ancien regime, no século XVIII, ela poderia ser pensada independentemente de uma crise que agravava por ocultá-la. Este é um argumento central de Reinhart Koselleck, em seu já clássico Kritik und Krise (1973), um livro que analisa a gênese da prática crítica no âmago do absolutismo. Com efeito, este surgiu como uma saída política para as guerras civis religiosas que ameaçavam dilacerar as sociedades européias; sua principal característica era a concentração total de poder na figura do monarca, cuja palavra tinha o estatuto de lei e que se encontrava desvinculada de qualquer consideração moral. A distinção entre política e moral tinha como correlato, assim, a expulsão da consciência da esfera política, o que implicava, para os que obedeciam, uma cisão radical entre súdito e homem, e para o rei uma grande independência para tomar decisões. $\mathrm{O}$ conceito de crítica ao monarca, nesse contexto, é o contrário do que se poderia esperar: não the mostrar o que lhe é vetado, mas o que de fato pode fazer, "mostrar-lhe seu direito. Isso significava, possivelmente, dar-lhe razão contra sua própria dor de consciência” (KoselLECK, 1973, p. 99). O Iluminismo emerge como um novo momento da 
dialética entre moral e política, que agora submete a segunda à primeira, e que dessa maneira encobre a política como tal. Sob a égide da consciência, e de seu dualismo de bem e mal, oculta-se a política e seu jogo de poder; a prática crítica adquire um aspecto temporal, uma vez que a perfeição (moral) sob a qual se ampara é projetada para o futuro, sob a forma do progresso. Ao obliterar o político, a crítica estaria, segundo Koselleck, desde o princípio, banhada em engodo.

É importante salientar que o argumento de Kritik und Krise deve ser relativizado, não para defender uma suposta pureza da crítica, mas para fazer jus à multiplicidade da crise, não apenas pela indeterminação de seu conteúdo (crise do quê?), mas diante de sua própria disseminação. Basta apenas um curto olhar sobre a diversidade de seu uso para que se dê conta de sua desconcertante abrangência. Quando começou a crise da modernidade? Com Descartes ou Kant? Com a Revolução Francesa ou a Industrial? Com Moisés, Jesus ou Lutero? Com Galileu ou Freud? Para o Adorno e Horkheimer, da Dialética do Esclarecimento, razão burguesa e crise sempre estiveram juntas, e esta última já seria detectável em Homero... Talvez seja mais frutífero, para lidarmos com essa verdadeira crise do conceito de crise, considerá-la menos como uma ocorrência histórica específica do que como uma categoria narrativa, uma estratégia de organização textual, a ser julgada por seu resultado, pela força explicativa que exibe e pelo cenário que descreve. No contexto que nos interessa, a crise da modernidade manifesta-se em uma problematização da própria prática crítica; em outras palavras, "crise" aqui é o termo que explica uma série de mutações no exercício da crítica, e cujo primeiro exemplo, aqui, é o de T.W. Adorno.

Vista como justificativa para a prática adorniana, a crise, nesse caso, refere-se à emergência de uma sociedade cuja racionalidade é irracional - um postulado que, de uma forma ou de outra, serve de denominador comum a toda Escola de Frankfurt. A intensificação do descompasso entre meios racionais e fins irracionais, a completa 
disposição do pensamento para a promoção dos atos mais bárbaros, cuja instância maior continua sendo Auschwitz, ainda que outras figuras de pensamento se façam necessárias (DurÃo, 2005a), tiram o ponto de apoio da prática crítica tradicional. Nem a história, nem a sociedade, nem a própria ratio podem ser tomadas como fontes fiadoras de alguma espécie de positividade. Mais que isso: a crítica vê-se obrigada a reconhecer que seu modus operandi está refletido, ainda que bizarramente destorcido, em seu próprio objeto. Muito facilmente recairia, através da assertividade com que aponta o erro, na dominação contra a qual se volta. Some-se a isso ainda outro fator relacionado a essa situação como um todo: o desaparecimento de um âmbito concreto de oposição. A prática crítica não faz muito sentido se desvinculada de uma esfera mínima de circulação - como é o caso do famoso texto de Kant, "O que é esclarecimento" (1985), no qual o uso público da razão fica reduzido aos sábios (Gelehrter) e ao mundo letrado (Leserwelt). A crítica perde sua razão de ser em uma sociedade que não mais lhe dá ouvidos, uma sociedade chamada por Marcuse de unidimensional, e que tem a prevenção ao pensamento crítico, ao pôr em questão, inscrita como princípio operacional, como um próprio pressuposto de seu funcionamento.

Talvez dentro desse contexto, a peculiar prática crítica de Adorno assuma um caráter menos excêntrico ainda que não menos hermético. É interessante notar que seu projeto crítico já se encontra delineado em seus primeiros escritos, posteriores à sua Dissertation e Habilitationschriften, agora recolhidos no primeiro volume de suas obras completas. São três textos, do começo dos anos 30, não muito conhecidos no Brasil, e que apresentam uma natureza programática pouco usual para Adorno, além de deixarem claramente entrever o quanto ele é tributário da filosofia de Walter Benjamin. Já em "A atualidade da filosofia”, a palestra inaugural de Adorno como professor de filosofia na Universidade de Frankfurt, em 7 de maio de 1931, encontram-se expostas algumas razões para a impossibilidade de exercer a crítica como antes. O texto começa enfaticamente: 
Quem hoje escolhe a filosofia como profissão deve desde o começo livrar-se da ilusão com a qual começaram os primeiros projetos filosóficos: que seria possivel, com o poder do pensamento, compreender [ergreifen] a totalidade do real. Nenhuma razão justificadora poderia redescobrir-se em uma realidade cuja ordem e formação suprimem toda pretensão à razão; é apenas polemicamente que esta se oferece ao sujeito do conhecimento como uma realidade inteira, enquanto somente em rastros e ruínas mantém viva a esperança de alcançar uma realidade correta e justa. (AdORno, 1973, p. 325)

A impossibilidade de exercer a crítica como antes é fruto de um desenvolvimento da objetividade, que leva a um descompasso entre os problemas filosóficos e a possibilidade de serem repondidos. Para Adorno, saber se a filosofia é atual depende da pergunta

se, depois do fracasso dos últimos grandes esforços, ainda existe uma adequação entre as questões filosóficas e a simples possibilidade de serem respondidas; se os próprios resultados da história recente destes problemas não corresponderiam a não serem essencialmente respondiveis as questões cardeais da filosofia. [...] Qualquer filosofia, hoje, que não se baseie na segurança das condições intelectuais e sociais vigentes, mas, ao invés, na verdade, vê-se confrontada com o problema do aniquilamento da filosofia. (Adorno, 1973, p. 331)

Se, devido ao próprio percurso da sociedade, a realidade converte-se em desrazão, os percursos de descoberta, os procedimentos interpretativos, adquirem uma relevância acentuada. A influência de Benjamin faz-se sentir fortemente quando Adorno defende um "método" que construa constelações a partir de elementos díspares, pondo lado a lado o dissimilar de forma a fazer surgir configurações inesperadas de sentido, inauditas, desprovidas de conteúdo volicional ou intencional, mas portadoras de verdade:

Uma interpretação filosófica autêntica [echte] não se depara com um sentido pronto por detrás de sua questão, mas ilumi- 
na-o repentina e momentaneamente, consumindo-o ao mesmo tempo. E da mesma forma com que se formam soluções para enigmas, quando elementos dispersos e singulares são unidos em vários grupos por tempo suficiente para que componham uma figura da qual surge a solução, enquanto a questão desaparece - da mesma forma a filosofia tem de formar constelações mutantes a partir dos elementos que recebe das ciências [...] até que constituam uma figura que possa ser lida como uma resposta, ao mesmo tempo em que a questão desapareça. (AdORno, 1973, p. 335)

Em suma, a perda da totalidade e a conseqüente dependência do poder crítico em restos, rastros ou ruínas, a necessidade de se formar constelações e o descrédito da intencionalidade como elemento de investigação - essas mutações, na prática crítica, são decorrentes de desenvolvimentos que tornaram a racionalidade do real irracional.

O segundo ensaio também é relevante. "A idéia de história natural”, uma comunicação apresentada em um encontro da seção frankfurtiana da Kant-Gesellschaft, em 1932, é sem dúvida um texto falho, mais "uma proposta metodológica, do que um conjunto de teses sobre o assunto" (Jameson, 1990, p. 94). ${ }^{2}$ Como aponta Robert Hullot-Kentor (1984) na introdução à tradução americana, o estilo de Adorno é ainda rígido, longe daquele que, posteriormente, tentaria reproduzir, em seu próprio movimento, a lógica do objeto. Além disso, outra observação de Hullot-Kentor, o termo "história natural”, em sua própria ambigüidade, que discutiremos a seguir, poderia ser visto como um neologismo, aparentando-se assim do hábito heideggeriano, contra quem Adorno se volta no ensaio. Apesar disto, porém, o texto tem um valor didático admirável, justamente devido à sua precariedade expositiva. Há também o notável fato de esse curto escrito apresentar uma forma de organização similar à da Dialética negativa, escrita trinta anos depois. A primeira parte do texto aborda o debate sobre a relação entre história e natureza a partir do neokantianismo, que se voltava sem 
sucesso contra a relatividade do historicismo que lhe antecedeu, recaindo em um formalismo que desconsiderava realidades históricas. A saida de Heidegger foi efetuar uma junção ao determinar a historicidade (Geschichtlichkeit) como central para a estrutura do ser. A crítica de Adorno, que seria retomada na Dialética negativa mais de trinta anos depois, defende que a historicidade do ser não é capaz de lidar com o fortuito ou com o contingente na história:

Pode-se erguer uma determinação estrutural geral da vida, mas se se tenta interpretar um fenômeno particular, como por exemplo a Revolução Francesa, embora seja possivel encontrar nela todos os componentes desta estrutura de vida - e.g. que o passado retorna e é retomado, que se pode verificar o significado da espontaneidade surgida no homem, que se podem descobrir contextos causais etc. -, não se conseguirá relacionar a facticidade da Revolução Francesa em seu ser factual mais extremo a tais categorias; pelo contrário, haverá, em sua dimensão mais ampla, uma esfera de "facticidade" a escapar. (AdORNO, 1973, p. 350)

Na segunda parte de "Idéia de história natural", Adorno introduz as principais diretrizes teóricas para pensar a imbricação de história e natureza, a saber, a noção de segunda natureza, exposta por Lukács na Teoria do romance, e de alegoria, como foi desenvolvida por Walter Benjamin na Origem do drama barroco. ${ }^{3}$ A primeira constituirá um filosofema nodal para Adorno, sem o qual faltaria à dialética adorniana sua mais forte mediação. Se a realidade social parece imediata é porque se configura como uma segunda natureza, o que é mais humano, a construção do mundo social, se apresentando como mais natural. É apenas dentro dessa dialética que o conceito de princípio de troca adquire todo seu peso em Adorno. Seu grau zero, por assim dizer, reside no encontro primordial com a natureza como aquilo que causa pavor e ameaça à autoconservação; o desenvolvimento do conceito como identidade, 
em última instância da própria razão, está ancorado no mundo natural. ${ }^{4} \mathrm{Na}$ sociedade totalmente socializada, completamente mediada pelo princípio de troca, o estranhamento retorna em um ambiente humano hostil: já estão aqui as bases para a Dialética do esclarecimento.

A influência de Benjamin em "Idéia de história natural" fazse sentir no conceito de alegoria como sendo capaz de expressar o transitório (Vergänglichkeit) da natureza: sua essência é o próprio devir e o poder de dissolução e declínio que o acompanha. Se a segunda natureza permite a Adorno pensar a dialética de sociedade e natureza, a definição desta última como passageira possibilita que se articule a oposição entre natureza e história. Nas palavras de Adorno:

A natureza, como criação que é pensada por Benjamin, é marcada pela transitoriedade. A própria natureza é transitória. Desta forma, possui em si o elemento da história. Sempre que algo de histórico surge, aponta de volta ao natural, que nele esvanece. Inversamente, sempre que a "segunda natureza" aparece (erscheint), quando o mundo da convenção aproximase de nós, é decifrado na medida em que seu sentido torna-se claramente o da transitoriedade. (Adorno, 1973, p. 359)

É assim que a explicação dos conceitos lukácsianos de segunda natureza e o benjaminiano de natureza como transitoriedade permitem a Adorno fundamentar o ponto central de seu texto, a saber, que a natureza é histórica e que a história é natural. Se, em "A atualidade da filosofia”, o pano de fundo da teoria é a constituição de uma totalidade antagônica (ao pensamento crítico e entre seus próprios componentes), cuja racionalidade é irracional, "A idéia de história natural” problematiza a noção de progresso e avanço: retomando o topos marxiano, a história é vista como ainda préhistórica.

O terceiro e último ensaio do primeiro volume das obras completas de Adorno é o curto "Teses sobre a linguagem do 
filósofo", publicado postumamente. Raramente comentado, é um interessante texto no qual são encontrados, de novo, argumentos muito mais diretamente expostos do que em sua obra posterior. Vale aqui ressaltar uma das dez teses propostas no texto. ${ }^{5}$ A quarta chama a atenção para a impossibilidade de a linguagem do filósofo ser claramente comunicável; com pendor dialético, observa que a própria exigência de comunicabilidade já aponta para sua impossibilidade:

Em uma sociedade homogênea, a compreensibilidade da linguagem filosófica nunca é exigida; ela é pelo contrário pressuposta: quando a força ontológica das palavras vai tão longe que tem conferido (zukommen) uma dignidade objetiva na sociedade. [...] $\mathrm{Na}$ ausência de uma sociedade fechada, não há uma linguagem objetiva e assim verdadeiramente compreensível. (AdORno, 1973, p. 367)

Em uma sociedade "aberta” (leia-se “moderna”), em uma sociedade fragmentada e de divisão de classes, a linguagem filosófica perde necessariamente sua transparência. Essa idéia inicial será então seguida de outras típicas de Adorno, como a crítica à intencionalidade e aos neologismos; a necessidade de fazer uso de uma terminologia tradicional em uma linguagem que, no entanto, deslocasse o sentido dos conceitos, ao apresentá-los em constelações; o fato de que "hoje, toda crítica filosófica é possível como crítica de linguagem [Sprachkritik]” (p. 369). Tudo isso leva, como conseqüência natural do raciocínio, a uma aproximação entre filosofia e arte - não apenas o próprio cerne da filosofia adorniana, mas também algo com ressonâncias importantes para uma filosofia posterior:

É possivel formular a crescente significância da crítica filosófica da linguagem como o sendo o começo de uma convergência entre arte e conhecimento. Enquanto a filosofia volta-se para a unidade imediata entre linguagem e verdade, até então pensada apenas esteticamente, e precisa avaliar dialeticamente 
sua verdade na linguagem, a arte adquire um caráter de conhecimento: sua linguagem só é esteticamente consistente (stimmig), quando é "verdadeira": quando suas palavras correspondem à situação (Stande) histórica objetiva. (ADORNO, 1973, p. 370)

Trata-se assim de três ensaios que promovem sérias modificações na prática crítica. Recapitulando: devido à irracionalidade de uma razão que se tornou total, a crítica debruça-se sobre fragmentos, rastros e ruínas ("A atualidade da filosofia”); por outro lado, a história, vista em "A idéia de história natural" como entrelaçamento do novo com o mesmo, com o mito, não fornece apoio, nem para uma reconciliação com o passado, nem como promessa de futuro; por fim, nas "Teses”, a própria linguagem crítica, ao dispensar a intencionalidade, conseqüentemente dependendo mais da imaginação, e ao dedicar-se à configuração de elementos díspares em constelações, aproxima-se da arte e do estético.

Crítica filosófica e crítica literária entram, dessa forma, em curso de colisão. Não que isso seja de todo surpreendente, já que esta última, à sua própria maneira, também fazia parte do processo de emancipação da burguesia do antigo regime (EAGLETON, 1984); todavia, é conveniente não se deixar levar pelo duplo uso da palavra "crítica" em português, e lembrar-se que o inglês faz a diferença entre criticism, a crítica literária, e critique, a filosófica. A primeira tem uma história própria, marcada por um longo período no qual “crítica” significava adequação do objeto literário a padrões consensuais de propriedade (o belo como algo a ser atingido, mais do que produzido). Como demonstrou Benjamin, foi apenas com o advento do romantismo que o artefato literário pôde ser concebido como entidade autônoma contendo em si, como em um microcosmo, uma totalidade. ${ }^{6}$ Mas há ainda, é claro, outros traços de disparidade entre a crítica literária e a filosófica, dentre os quais vale citar a rivalidade entre arte e filosofia, verdadeira corrente subterrânea na história do pensamento, que tantas vezes levantou 
a suspeita de que a imaginação artística estava fadada ao quimérico, mas que, por outro lado, se fez sentir como erupção em momentos de crise. Talvez seja isso que acontece hoje. Nas últimas décadas, a prática crítica testemunhou importantes modificações, que necessitam urgentemente de apreciação. A confluência entre crítica literária e filosófica pode ser vista como parte do movimento mais amplo de surgimento daquilo que já é chamada simplesmente de teoria, uma formação discursiva que desafia a própria idéia de campo ou área (DURÃo, 2005b). ${ }^{7}$

Gostaria de abordar, em linhas bem gerais, três casos relevantes, nos quais a crítica, não apenas em sua forma tradicional, mas também em sua reformulação adorniana, é desafiada e levada a limites que antes não eram nem mesmo visíveis como tais. São três filosofias, igualmente complexas - de fato, formas de pensamento que desafiam a própria idéia de filosofia; não é questão, aqui, de discutir seu conteúdo, nem mesmo de fazer-lhes um comentário mínimo, mas de chamar a atenção, de fora e de cima, para seu modus operandi dentro do contexto da prática crítica. Trata-se, em outras palavras, de sublinhar o quanto essas versões contemporâneas da crítica abolem a idéia de objeto por meio de três procedimentos particulares: a dissolução de sua totalidade, a indiferenciação entre ele mesmo e o aparato de leitura utilizado para interpretá-lo, e, por fim, a redução absoluta da distância hermenêutica.

Há, assim, em primeiro lugar, Jacques Derrida, um autor prolifico, cujo ensaio "Duas palavras para Joyce” (1987) poderá servir de referência. Do Finnegans Wake são retiradas duas palavras: HE WAR, que Derrida então insere em uma rede de referencializações para demonstrar a impossibilidade da existência das palavras. Que as palavras não existam como tais, que não sejam unidades de sentido, não nos é dado como hipótese - se o fosse representaria uma contradição, em termos, afirmar o que faz impossível a afirmação - mas com uma pergunta: "O que é uma palavra?" (DERridA, 1987, p. 15). ${ }^{8}$ Em seguida, Derrida, começa o trabalho de tessitura com uma primeira tradução das duas palavras: "ele guerra"; 
mas em seguida sugere, também, "ele foi" com war como passado do alemão sein. Daí vem a associação bíblica: "ele foi aquele que foi. Eu sou aquele que é, que sou, sou quem sou, teria dito Yahwé" (p. 16). Um terceiro passo une os dois: "Lá, onde era, ele foi, declarando a guerra. E isso foi verdade [...] wahr. Eis o que se pode guardar (wahren, bewahren) de verdade [en vérité]”. A frase seguinte lança um novo dado, ligado a uma expressão fixa do francês e do português, para a qual simplesmente não pode haver uma explicação, "declarar guerra": "Deus evita (se garde). Evita-se assim de declarar guerra” (p. 17). Uma guerra entre as línguas, já que Derrida está lidando com o francês e o alemão. "Declarar é um ato de guerra, ele declarou a guerra em línguas, à língua e pela língua” (p. 17). "Palavra”, "guerra”, “ser”, “Deus”, "guardar”, “declarar”, mas também "ser breve” (deux mots) são todos fios que Derrida irá tecer em sua malha discursiva. E não é de se espantar que em seguida, depois de lançá-los, observe: "Paro aqui, provisoriamente, por falta de tempo. Outras transformações permanecem possíveis, um grande número, sobre as quais ainda direi duas palavras daqui a pouco" ( $\mathrm{p}$. 17). Essas descontinuidades, que apontam para uma forte presença de um eu enunciador, na realidade desempenham o papel de um gesto estruturador do texto; sem elas seria impossível interromper a tessitura e continuar.

É importante notar nesse contexto que a prática crítica (e a filosofia de Derrida se quer ver como tal) dispensa qualquer pretensão de totalidade no objeto. $\mathrm{O}$ detalhe, que em Adorno ainda estava em tensão com o todo, com uma totalidade, adquire aqui uma total autonomia: não o Finnegans Wake, mas duas palavras. Por certo, seria possível argumentar que he war seria representativo do livro como um todo, que o desdobrar dos sentidos e a construção das associações teriam o estatuto de exemplo, ou mesmo de convite para demais leituras. Isto seria válido se não se chocasse com a experiência empírica de leitura da obra de Joyce; para que faça sentido, um mínimo de velocidade decodificadora é necessário. É impossível parar a cada palavra para investigar sua metaforicidade ou 
polissemia; para que haja um mínimo de enredo, o leitor é obrigado, via de regra, a atribuir um sentido primário às palavras para poder seguir adiante. De novo, um derridiano poderia observar que esse próprio argumento prova a impossibilidade da leitura, algo que Derrida por décadas defendeu. Isto, no entanto, só faria realçar o conceito de totalidade implícito nesse caso: uma totalidade totalitária, que almejasse apreender todas as referências do Finnegans Wake, todas as possibilidades de disseminação e deslocamento de sentido oferecidas pelo texto. ${ }^{9}$ Seja como for, Derrida, ele mesmo, evita generalizações a partir de sua própria prática crítica; com efeito, a forma mais proveitosa de abordar sua escrita reside em encarar sua radical intransitividade, que, mutatis mutandis, também está presente em Adorno. Derrida demonstra - pelo menos em seus melhores momentos - a impossibilidade daquilo que parecia ser o mais sólido, mas sem extrapolar ou generalizar a partir disso. ${ }^{10}$

Se com a crítica derridiana perde-se a tensão entre o particular e a totalidade do/no objeto, uma outra tendência surgiu recentemente que precariza a relação entre objeto e instrumento de análise. Trata-se do lacanismo de esquerda da Escola de Llubliana, cujo representante mais conhecido é Slavoj Žižek. ${ }^{11}$ Em vários casos, os títulos dos livros combinam termos psicanalíticos com outro item (como no Ethics of the Real, de Zupanèiè, uma bela leitura lacaniana da ética kantiana), mas a prática de Žižek é mais extrema. Em certo sentido é possível dizer que seus vários livros (eis aqui, também, um escritor prolixo) são na realidade um só. É difícil determinar o assunto de cada um deles, pois o material a ser analisado parece na maior parte das vezes servir como explicação da teoria, do aparato interpretativo lacanino; torna-se como que um pretexto para um estonteante virtuosismo hermenêutico. Isso explica algo do thrill do texto žižekiano: a mistura de filosofia com escatologia, de preciosos insights de arte com anedotas e piadas, todas sustentadas por conceitos do Sr. Lacan. 
Tomemos Plagues of phantasies (1997), um de seus livros mais famosos. O texto filia-se a uma longa tradição de crítica ideológica, como deixa claro seu plano inicial:

Nos velhos tempos da Ideologiekritik tradicional, o procedimento crítico paradigmático era direcionar-se de noções "abstratas" (religiosas, legais...) para a realidade social na qual tais noções estavam enraizadas; hoje, parece que o procedimento crítico é forçado cada vez mais a seguir o caminho oposto, de imagens pseudoconcretas para processos abstratos que estruturam verdadeiramente nossa experiência de vida. (Žižek, 1997, p. 1)

O conceito lacaniano de fantasia - aquilo que organiza o mundo representacional do sujeito, bem como o que o protege contra o encontro destruidor do real - será o instrumento teórico que levará a crítica a cabo. O gesto típico de Žižek é trazer a fantasia para a análise ideológica, como na já célebre análise das latrinas alemãs, francesas e americanas e sua forma lidar com a matéria fecal. Falta, no entanto, no discurso žižekiano, a categoria fundamental da mediação: das latrinas passa-se para o Paraiso perdido, de Milton, depois para um conto de fadas antiaborto de um poeta direitista esloveno, a Venus de Milo, Edith Warton... O elemento de coesão do livro, que outrosssim explodiria em uma série de anedotas e análises isoladas, são as próprias categorias lacanianas, que passam a representar o esqueleto do texto, aquilo de que os objetos do mundo falam, tanto ou mais do que o contrário. Não se sabe, em suma, se Lacan explica o mundo, ou se o mundo explica Lacan.

O terceiro caso refere-se à prática de leitura de Deleuze e Guattari, como em seu Franz Kafka: para uma literatura menor. As frases iniciais do livro: "Como se tem acesso à obra de Kafka? Ela é um rizoma, uma construção.” Já aqui há uma estranha predicação: "rizoma", ainda que um termo existente na botânica, representa um conceito fundamental para Deleuze e Guattari. A obra de Kafka 
não é vista como um rizoma, mas o é pura e simplemente. Trata-se aqui de uma crítica que abole o objeto, não como em Derrida, por meio do detalhe infinito, mas pela dissipação da distância hermenêutica. Isso fica claro no começo do segundo parágrafo do livro:

Escolhamos uma entrada modesta: em $\mathrm{O}$ Castelo, bem no começo, K. Descobre no quarto [Wirtstube] o Retrato de um porteiro com a cabeça abaixada, o queixo pressionando fortemente o busto. Ambos os elementos - retrato ou foto e cabeça abaixada, pressionando para baixo - encontram-se, de forma mais ou menos marcante, por todos os lugares em Kafka. (Deleuze e Guattari, 1976, p. 7)

O retrado e a cabeça abaixada são elementos recorrentes nos textos de Kafka; itens imanentes ao texto não são traduzíveis imediatamente para o discurso crítico. Têm, antes, de entrar em processo de equivalência ou predicação ("cabeça abaixada" = "x") e a inadequação ou desnível estrutural entre sujeito e predicado justificam a idéia de um círculo hermenêutico, que dirige uma segunda leitura para o resultado da primeira. Há, assim, no processo interpretativo tradicional uma determinada distância que não pode ser completamente abolida. Ora, Deleuze e Guattari são bastante claros quanto a isto: lidar com a cabeça abaixada e com o retrato é justamente o que não querem fazer. Ao invés, introduzem uma série de conceitos como "máquina”, "encadeamento" e "desencadeamento”, "tornar-se animal”, “(des)territorialização”. Note-se bem, tais termos não são aplicados ao texto kafkiano, mas, pelo contrário, são tidos como inerentes a ele. São, por outro lado e simultaneamente, ferramentas do pensamento deleuzo-guattarianas. Já não há mais qualquer distância entre o objeto de crítica e o discurso crítico; ao impor categorias ao texto, a análise violenta-o, uma violência que poderia ser defendida pelos autores ao dizer que é mais legítima que a outra, velada, que faz uso dos termos do texto, mas os desloca para seus próprios fins. 
Cada uma dessas modalidades de crítica traz em si potências e riscos misturados; a despeito de sua singularidade, apresentam, contudo, importantes pontos de contato. É tarefa da crítica discernir o que está em jogo nessas práticas críticas, o que oferecem e, ao mesmo tempo, impossibilitam. Não resta dúvida que o que o oferecem é sentido: dificilmente o leitor atento passa incólume por esses autores, sem ser pego de surpresa por aquilo que formulam. São críticos, em suma, que fisgam. Derrida constrói impossíveis (o impossível erigido ao estatuto de categoria); Žižek aponta para a lógica comum subjacente aos mais díspares fenômenos; Deleuze e Guattari promovem uma releitura do cânone literário-filosófico, tornando-o compatível com o que há de mais contemporâneo, como a realidade virtual. Nos três casos observa-se, também, o benéfico efeito daquilo que já há algum tempo foi anunciado, por Roland Barthes e tantos outros, como transição da "obra" para o "texto". O ganho em liberdade é inegável; em comparação com a prática crítica de Adorno, é inútil apontar, por exemplo, para sua estima por Chaplin, ou até mesmo defender que a categoria "obra" não é um dado, mas uma construção do próprio ato interpretativo, sendo atribuída sempre a posteriori. É a dissolução da obra, ligada àquilo que foi chamado anteriormente de desaparecimento do objeto, que permite que seja fraturado (Derrida), conectado a elementos aparentemente díspares (Žižek) e imbuído de teoria (Deleuze e Guattari).

O preço a ser pago pela forte produção de sentido e a liberdade decorrente disso são, porém, determinados. ${ }^{12}$ Em Derrida, perdese o princípio de individuação, justamente porque o detalhe perde a tensão, ainda existente em Adorno, com o todo. Quanto à Žižek, a mistura de teoria e objeto, instrumento e fenômeno, impede que haja sobras, seja em um ou no outro: a realidade se esgota em sua análise à medida que o aparato conceitual aparece como soberano. Faltam restos à teoria que melhor tematizou a falta. Por fim, em Deleuze e Guattari, a presença da teoria na realidade flerta com um dos mais antigos conceitos críticos, o da alienação. $\mathrm{O}$ afrou- 
xamento nesse caso se dá entre a experiência e o conhecimento, uma vez que esta, por vezes, nega a adequação da realidade à teoria, insistindo em uma pobreza constitutiva que resiste à produção. Tudo isso conduz ao que há de mais insatisfatório nessa virada do pensamento crítico: o evanescimento do seu caráter normativo. $\mathrm{O}$ sollen, o "deveria-ser", que de uma forma ou de outra está implicado na prática crítica nos pensadores da Escola de Frankfurt (que é ainda mantido, enfraquecidamente, mesmo em Habermas) não tem aqui nenhuma razão de ser. Note-se bem, não se trata de lamentar a ausência do apelo à práxis, um gesto argumentativo já tão desgastado, mas de constatar a desintegração daquele "poderia-seroutro" que alimentou tanto da crítica até hoje. Permanece assim a questão: até que ponto a crítica a essas críticas pode absorver seus momentos positivos sem abrir mão de um ser-outro concretamente possível? Uma pergunta que, paradoxalmente, tem como pressuposto o próprio esvanecer da crítica, proporcionada, por assim dizer, pelos contornos de seu próprio desaparecimento.

\title{
MUTATIONS IN CRITICAL PRACTICE
}

\begin{abstract}
The essay investigates recent developments in philosophical critique. In its first part, it draws in broad strokes the main determinations of the concept of critique, at the same time that it establishes a link between critique and crisis. This is followed by a description of T.W. Adorno's critical practice, where it is highlighted: a. the valorization of micrological reading in the context of the waning of the concept of totality; b. the problematization of linear temporality through the intertwining of history and nature; $\mathrm{c}$. a growing opacity in terms of philosophical language vis-à-vis its object. The last part of the text is devoted to recent versions of critique that take Adorno's changes to an extreme degree. In Derrida, there is the autonomization of detail; in Slavoj Žižek one loses sight of the difference between object and instrument of analysis; in Deleuze \& Guattari one witnesses the dissolution of hermeneutical distance.
\end{abstract}

Key words: Critique, T.W. Adorno, theory.

\section{Notas}

1. Sigo aqui em grande medida o ensaio de Wolfgang Bonß, "Warum ist die Kritische Theorie kritisch?" (DEmiroviè, 2003). 
2. O capítulo chamado "História natural", do livro de Jameson, é de grande interesse.

3. Sigo aqui o bom comentário de Link (1986, p. 33-51).

4. Há uma interessante diferença neste contexto entre as concepções de Adorno e Benjamin, em relação à filosofia do nome, que valeria a pena ser explorada. Para o primeiro, o ato de nomear é fruto do medo: como estratégia de identificação com o agressor, já representa um mecanismo de dominação; para Benjamin, o nome guarda em si algo de adâmico, anterior à Queda.

5. Talvez fosse proveitoso investigar a forma de teses para o pensamento de Adorno. Diferentemente de Benjamin, cujas "teses" são conhecidíssimas, tal forma de exposição é rara em sua obra, estando presente apenas no "Teses sobre a carência” ("Thesen über Bedürfnis”), no GS 8 .

6. Cf. também o clássico de Abrams (1953).

7. Para dar um exemplo concreto: o pós-modernismo (1991), de Fredric Jameson, não é classificável como texto filosófico, ou de crítica literária etc.

8. Estabeleço uma articulação inicial de Adorno e Derrida em "Adorno e Derrida: uma tentativa de aproximação" (no prelo). É interessante notar, de passagem, a oposição diametral entre os dois na modalidade: Derrida, um filósofo que pergunta incessantemente; Adorno, um que assevera, que nunca usa o ponto de interrogação.

9. Há ainda um outro espectro de totalidade a rondar alguns textos de Derrida e a grande maioria de seus divulgadores: o conceito de metafísica ocidental, ou metafísica da presença, que é caracterizada como uma perfeita identidade, à qual será contraposta a diferença, o rastro, o jogo etc.

10. Isto gera, sem dúvida, uma posição embaraçosa em Espectros de Marx, quando Derrida, ao propor uma assombrologia 
(hauntology, em inglês), ao invés de um ontologia de Marx, parece fechar as portas para um socialismo futuro.

11. Outros membros desta escola, não menos interessantes, são Mladen Dolar, Alenca Zupanèiè, Renata Salecl, entre outros.

12. É apenas sob o pano de fundo daquilo que de fato conseguem que a crítica a esses pensadores, assim como ao pós-estruturalismo em geral, deve ser levada a cabo. O procedimento, tão comum entre os marxistas, de recusa abstrata e seu argumento de fundo, a dureza da vida social, desembocam na total falta de liberdade, na absoluta determinação.

\section{Referências}

Abrams, M. H. The mirror and the lamp. Oxford: OUP, 1953.

Adorno, T. W. Die Aktualität der Philosophie. Gesammelte Schriften 1. Frankfurt a.M.: Suhrkamp, 1973.

. Die Idee der Naturgeschichte. Gesammelte Schriften 1. Frankfurt a.M.: Suhrkamp, 1973.

. Thesen über die Sprache des Philosophen. Gesammelte Schriften 1. Frankfurt a.M.: Suhrkamp, 1973.

Benjamin, W. Sobre o conceito de crítica de arte no romantismo alemão. São Paulo: Iluminuras, 2002.

Deleuze, G.; Guattari, F. Franz Karka. Tradução de B. Kroeber. Frankfurt a.M.: Suhrkamp, 1976.

Demiroviè, A. (Ed.). Modelle kritischer Gesellschaftheorie. Traditionen und Perspektiven der kritischen Theorie. Stuttgart: J.B. Metzler, 2003.

DerridA, J. Deux mots pour Joyce. Ulysse gramophone. Paris: Galilée, 1987.

Durão, Fabio A. Adorno in Brazil. Atenea, Porto Rico, 2005a. [No prelo]. 
. Breves observações sobre a teoria, suas contradições e o Brasil. Revista de Letras, Unesp, 2005b. [No prelo].

Adorno e Derrida: uma tentativa de aproximação. Forum Deutsch, UFRJ, 2005c. [No prelo].

Eagleton, T. The function of criticism. Londres: Verso, 1984.

Jameson, F. Late Marxism, Adorno, or, The persistence of the dialectic. Londres: Verso, 1990.

Hullot-Kentor, Robert. Introduction to Adorno. Telos, n. 60, p. 97-110, Summer 1984.

Kant, I. O que é esclarecimento? Textos seletos. Tradução de Raimundo Vier e Floriano de S. Fernandes. Petrópolis: Vozes, 1985.

Koselleck, R. Kritik und Krise. Eine Studie zur Pathogenese der bürgerlichen Welt. Frankfurt a.M.: Suhrkamp, 1973. [1. ed. 1959]. Link, T. Zum Begriff der Natur in der Gesellschaftstheorie Theodor W. Adornos. Viena: Böhlau Verlag, 1986.

ŽıžEK, S. Plague of phantasies. Londres: Verso, 1997. 